\title{
Iris melanomas: are they more frequent in New Zealand?
}

Melanomas are the most common primary neoplasms of the iris ${ }^{1}$ with an incidence reported to range between $0.019-0.08 / 100000$ inhabitants/year. ${ }^{2-5}$ Jensen, $^{3}$ in Denmark, has observed a recent increase in the incidence of these tumours and suggested that the increase in ultraviolet solar radiation might be responsible. In New Zealand solar ultraviolet radiation is high and levels are increasing as a result of depletion of the ozone layer over Antarctica. New Zealanders tend to spend large amounts of time out of doors, their predominant ethnicity is white, and they have a high frequency of solar related tumours. ${ }^{6}$ If a cause and effect relation exists between sunlight exposure and iris melanomas an increased number of these tumours might be anticipated. To explore this relation we reviewed data of patients with iris melanomas to determine the incidence of these tumours in the South Island of New Zealand and to compare it with countries for which this information is available.

All iris tumour surgery is likely to be undertaken in two university affiliated hospitals (Christchurch and Dunedin) whose catchment population is the entire South Island of New Zealand. Files of all patients from these centres who had surgery for presumed iris melanoma in the years 1984-98 (15 year period) were reviewed. For inclusion in the analysis, patients had to be permanent residents of the South Island, have comprehensive clinical records, and a histological specimen available for review. Histology slides were obtained from all lesions and they were examined in masked fashion by two experienced ocular pathologists. For analysis, the malignant category consisted of spindle B, epithelioid, and mixed tumours, and all other histological diagnoses (spindle A, low grade spindle, and melanocytoma) were assigned to the benign group. Population data for the calculation of incidence were provided by Statistics New Zealand.

In the 15 year study period (1984-98) 16 white patients had surgery for melanocytic iris tumours in Christchurch (14 patients) and Dunedin (two patients). Patient data at the time of surgical intervention and histological diagnoses are shown in Table 1.

There was an equal number of men and women in the series with a mean age of 48.6 years. Malignant tumours were larger, with a mean basal diameter of $4.8 \mathrm{~mm}$ compared with benign tumours $(3.1 \mathrm{~mm})(\mathrm{p}=0.016)$. The

Table 1 Summary of patient data

\begin{tabular}{llllll}
\hline No & Sex & Eye & Age & Basal diameter & Histological diagnosis \\
\hline 1 & F & R & 70 & 4 & Mixed \\
2 & M & R & 49 & 3 & Spindle A \\
3 & F & L & 31 & 4.3 & Mixed \\
4 & F & L & 44 & 4.7 & Low grade spindle \\
5 & M & L & 34 & 4.2 & Mixed \\
6 & M & L & 63 & 5.2 & Mixed \\
7 & F & L & 64 & 2.3 & Spindle A \\
8 & F & L & 62 & 7 & Spindle B \\
9 & F & L & 57 & 5 & Spindle B \\
10 & F & R & 52 & 3.9 & Epithelioid \\
11 & M & L & 62 & 4 & Mixed \\
12 & F & R & 24 & 3 & Low grade spindle \\
13 & M & R & 40 & 4 & Spindle B \\
14 & M & R & 58 & 6.3 & Epithelioid \\
15 & M & L & 48 & 4.6 & Epithelioid \\
16 & M & L & 20 & 3 & Melanocytoma \\
\hline
\end{tabular}

Table 2 Incidence of iris melanoma in various countries

\begin{tabular}{|c|c|c|c|c|}
\hline Country & $\begin{array}{l}\text { Incidence, all } \\
\text { excised iris } \\
\text { tumours } \\
\text { (tumours/ } \\
100 \text { 000/year) }\end{array}$ & $\begin{array}{l}\text { Incidence, } \\
\text { malignant iris } \\
\text { tumours } \\
\text { (tumours/ } \\
\text { 100 000/year) }\end{array}$ & $\begin{array}{l}\text { Total number } \\
\text { of tumours } \\
\text { reported } \\
\text { (excised) }\end{array}$ & Reference \\
\hline Denmark & 0.07 & 0.06 & 80 & 3 \\
\hline Finland & 0.02 & $?$ & 11 & 5 \\
\hline Northern Ireland & 0.04 & 0.03 & 9 & 2 \\
\hline Iceland & 0.08 & 0.08 & 4 & 4 \\
\hline New Zealand & 0.13 & 0.09 & 16 & this report \\
\hline
\end{tabular}

^For calculations of the incidence of malignant iris tumours the following histological diagnoses were included in malignant groups: Jensen ${ }^{3}$ : spindle, epithelioid, mixed; Raivio ${ }^{5}$ : not possible to determine; McGalliard and Johnston ${ }^{2}$ : spindle B, mixed; Gislason et $a l^{4}$ : spindle B, epithelioid; this report: spindle B, mixed, epithelioid.

average time from initial presentation to surgery was 3.25 $(0-15)$ years. Seven of eight tumours excised within 3 months from initial presentation were malignant and were $4.00 \mathrm{~mm}$ or more in diameter. The exception was a $3 \mathrm{~mm}$ tumour in a prison inmate, who was worried that he could be lost from follow up and wanted to have the tumour excised All five benign category tumours had documented growth with an average observation time of 4.8 years.

In the 12 years from 1986 to 1997 the average population of South Island was 886 792. The largest nonEuropean ethnic group was Maori, they constitute $5.5 \%$ of population in the South Island. After their exclusion, the average population of South Island was 838018 people (and this represents people mainly of European descent and smaller (around or under 1\%) minorities of Asians, Pacific Islanders, and others). The calculated incidence of melanocytic iris tumours for this population is $0.13 /$ 100000 inhabitants/year. For malignant tumours (spindle $\mathrm{B}$, epithelioid, and mixed tumours) the calculated incidence is $0.09 / 100000$ inhabitants/year.

The incidence of iris melanoma in New Zealand South Island (0.9/100 000 inhabitants/year) is higher than in other countries from which this information is available (Table 2). The difference in ultraviolet radiation between New Zealand and these northern European countries is not known, but will probably be close to that reported for Germany. Seckmeyer and McKenzie ${ }^{7}$ found the DNA damaging ultraviolet radiation 1.9 times higher in New Zealand compared with Germany (in summer of years 1990-1). Since then, ultraviolet (UV) B radiation has increased over $12 \%$ in New Zealand. ${ }^{8}$ These high rates of damaging ultraviolet radiation are paralleled by high incidence of skin melanoma. The incidence of this tumour on the face is three times higher in New Zealand than in Canada, even though the populations have reasonably similar, primarily European, ancestry. ${ }^{6}$

Ultraviolet light is a part of the invisible solar radiation with the wavelength of 100-400 $\mathrm{nm}$. The shortest of these wavelengths (UV-C, 100-280 nm) are essentially completely blocked by atmospheric oxygen and ozone. The UV-B region of the spectrum $(280-315 \mathrm{~nm})$ is absorbed efficiently, but not completely by ozone, while UV-A rays $(315-400 \mathrm{~nm})$ are absorbed only weakly. ${ }^{9} \mathrm{UV}-\mathrm{B}$ is the most mutagenic part of the spectrum, typically causing C-T substitutions. ${ }^{10}$ These were found both in oncogenes and tumour suppressor genes in skin melanoma. ${ }^{11}$ UV-A, 
although biologically much less potent than UV-B, can induce mutations, ${ }^{11}$ mainly DNA strand breaks and DNA crosslinks. ${ }^{12}$

Iris tissue is exposed both to UV-A and UV-B radiation. While the cornea absorbs most of the radiation below 300 $\mathrm{nm},{ }^{13}$ all of the UV-A spectrum and part of the UV-B radiation wavelength reach the iris. The most shielded part of the iris is the superior area covered by the upper lid. This is also the area where melanomas are rare. In our study there was only one tumour located superiorly, and it was a spindle A tumour. In the study of Teritto et $a l^{14}$ only 14 out of 175 tumours were located superiorly, and none of them grew during the follow up. This observation could be analogous to the lower incidence of skin melanoma on areas protected from chronic sun exposure. ${ }^{6}$

It is important to note that the global comparisons of ultraviolet radiation might not be accurate for ocular exposure. Sliney ${ }^{13}$ has shown that more ultraviolet radiation reaches the eye through scatter from clouds and reflections from the ground surfaces than from direct sunlight. The radiation entering the eye is the sum of radiation coming from horizon sky and ground reflection. When the horizon sky is blocked by buildings or mountains the amount of ultraviolet radiation is decreased. Thus, the ocular ultraviolet exposure would generally be high in New Zealand, where most of the population lives on flat or rolling hills and close to the ocean (with high reflection for ultraviolet).

We consider unlikely the possibility of excision of an iris tumour outside the two tertiary centres which participated in the study. If it has occurred the incidence of iris melanomas in South Island would be even higher. A significant difficulty in comparing the calculated incidences from different countries arises from the infrequency of iris melanoma and sampling errors associated with small numbers. Also, the numbers of reported malignant tumours are dependent on the pathological classifications employed..$^{2-5}$ While Gislason et $a l^{4}$ and McGalliard and Johnston ${ }^{2}$ described the melanomas as spindle A, B, epithelioid, or mixed, Jensen ${ }^{3}$ used spindle, mixed, epithelioid, and naevoid; and Raivio ${ }^{5}$ spindle cell and mixed cell types. Lastly, the clinical readiness to excise iris tumours varies from country to country and between surgeons.

We have shown that the incidence of iris melanocytic lesions treated by excision was higher in the South Island of New Zealand than that reported for other countries.
High solar UV-B radiation in New Zealand could be a factor contributing to this observation. Other factors, including possible differences in clinical practice, have to be considered. To establish the true incidence the numbers of both observed and excised tumours will have to be collected in various countries. The potential association between solar radiation and malignant iris melanoma supports the use of sunglasses with ultraviolet filters in situations of risk, particularly when long term predictions of ultraviolet radiation levels are uncertain. ${ }^{9}$

This study was in part supported by the Canterbury Medical Research Founda-

We would like to thank Dr Richard McKenzie from New Zealand National Institute of Water and Atmospheric Research for providing the information about ultraviolet radiation and Mr Ian Jury from Canterbury Health Laboratories for his technical assistance.

KIRA MICHALOVA RICHARD CLEMETT ALEX DEMPSTER JANE EVANS

RANDALL A ALLARDYCE

Departments of Ophthalmology, Surgery and Pathology, Christchurch Hospital and School of Medicine; and Southern Community Laboratories, Ltd, New Zealand

Correspondence to: R Clemett

RClemett@chhlth.govt.nz

1 Brown D, Boniuk M, Font RL. Diffuse malignant melanoma of iris with metastases. Surv Ophthalmol 1990;34:357-64.

2 McGalliard JN, Johnston PB. A study of iris melanoma in Northern Ireland. Br f Ophthalmol 1989;73:591-5.

3 Jensen OA. Malignant melanoma of the iris. A 25-year analysis of Danish cases. Eur f Ophthalmol 1993;3:181-8.

4 Gislason I, Magnusson B, Tulinius H. Malignant melanoma of the uvea in Iceland 1955-1979. Acta Ophthalmol 1985;63:389-94. 5 Raivio I. Uveal melanoma in Finland. An epidemiological, clinical, histological and prognostic study. Acta Ophthalmol (suppl) 1977;133:1-64.
Bulliard JL, Cox B, Elwood JM. Comparison of the site distribution of Bulliard JL, Cox B, Elwood JM. Comparison of the site distribution
melanoma in New Zealand and Canada. Int f Cancer 1997;72:231-5.

7 Seckmeyer G, McKenzie RL. Increased ultraviolet radiation in New Zealand $\left(45^{\circ} \mathrm{S}\right)$ relative to Germany $\left(48^{\circ} \mathrm{N}\right)$. Nature $1992 ; 359: 135-7$

8 McKenzie R, Connor B, Bodeker G. Increased summertime UV radiation in New Zealand in response to ozone loss. Science 1999;285:1709-11.

9 Madronich S, McKenzie RL, Bjorn LO, et al. Changes in biologically active ultraviolet radiation reaching the earth's surface. In: Environmental Effects of Ozone Depletion:1998 Assessment. Nairobi: UNEP (United Nations Environment Programme), 1998:1-27.

10 Mitchell DL, Jen J, Cleaver JE. Sequence specificity of cyclobutane pyrimidine dimers in DNA treated with solar (ultraviolet B) radiation. Nucl Acid Res 1992;20:225-9.

11 Quinn AG. Ultraviolet radiation and skin carcinogenesis. $\mathrm{Br} \mathcal{F}$ Hosp Med 1997:58:261-4.

12 Peak MJ, Peak JG. Solar-ultraviolet-induced damage to DNA. Photodermatol 1989;6:1-15.

13 Sliney DH. Ultraviolet radiation effects upon the eye: problems of dosimetry. Radiation Protection Dosimetry 1997;72:197-206.

14 Territo C, Shields CL, Shields JA, et al. Natural course of melanocytic tumors of the iris. Ophthalmology 1988;95:1251-5. 